\title{
Thermocycling effect on microshear bond strength to zirconia ceramic using Er:YAG and tribochemical silica coating as surface conditioning
}

\author{
Ana Luísa Gomes, João Carlos Ramos, Sergio Santos-del Riego, Javier Montero, \\ Alberto Albaladejo
}

\begin{abstract}
The purpose of this study is to evaluate the thermocycling effect on the microshear bond strength ( $\mu$ SBS) of different self-adhesive resin cements to zirconia using tribochemical silica coating Rocatec ${ }^{\mathrm{TM}}$ (ROC) and Er:YAG as surface conditioners. Two hundred forty square-like zirconia samples were polished and randomly assigned in four groups according surface treatment applied as follows: (1) no treatment (NT), (2) silica coating with ROC, 3) Er:YAG laser irradiation (LAS: $2.940 \mathrm{~nm}, 200 \mathrm{~mJ} ; 10 \mathrm{~Hz}$ ), and (4) laser followed by Rocatec ${ }^{\mathrm{TM}}$ (LAROC). Each group was divided into two subgroups according the resin tested as follows: (A) BiFix SE (BIF) and (B) Clearfil SA (CLE). After $24 \mathrm{~h}$, half of the specimens from each subgroup were tested. The other half was stored and thermocycled (5$55^{\circ} \mathrm{C} / 5,000$ cycles). A $\mu$ SBS test was performed using a universal testing machine (cross head speed $=0.5 \mathrm{~mm} / \mathrm{min}$ ). Failure modes were recorded and observed by scanning electronic microscopy. Data was analyzed with ANOVA, Student's $t$ test, and chi-square tests, and linear regression was performed $(p<0.05)$. Before thermocycling, both cements showed higher $\mu$ SBS results with ROC and LAROC. After aging, (1) all BIF specimens evidenced severely decreased adhesion with mostly adhesive failures and (2) CLE maintained the initial results in ROC and LAROC groups, performing better with ROC. Thermocycling did not negatively influence the resin-zirconia $\mu$ SBS results in the self-adhesive resin cement containing 10-MDP when used on zirconia surface coated with silica, independently of previous Er:YAG surface treatment.
\end{abstract}

Keywords

Er:YAG Zirconia Adhesion Silica coating Thermal aging $\mu$ SBS

\section{Introduction}

The use of zirconia ceramics as a dental restorative material is now the focus of extensive clinical, research, and industrial activity. Due to its mechanical properties, combined with its biocompatibility and optical benefits, yttrium stabilized tetragonal zirconia (Y-TZP) has become widely used in esthetic dentistry $[1,2]$.

The long-term performance and adhesive effectiveness of ceramic prostheses depend strongly on the cementation procedure [3]. Among the resin cement luting systems currently available, self-adhesive resin cements are a relatively new category of resin luting agents claimed to provide good bond strengths to tooth structures and restorative materials without any pretreatment or bonding agents [4]. They are widely used because of their properties and the cementation technique's simplicity [5].

There is no consensus regarding the best surface conditioning method for achieving optimal bond strength between composite resins and zirconia. Several adhesive strategies have been suggested to overcame this issue by changing the ceramic surface, including (1) new surface roughening procedures $[6,7],(2)$ chemical bonding [8-11], and (3) laser treatments [12, 13].

With the purpose of cleaning the surfaces, creating a highly retentive surface, and most of all, enhancing their silanizability, there are several methods to silicatize, i.e., silica coat, prosthodontic material surfaces. Tribochemical silica coating can be used chairside in the form of sandblasting, with a specifically surface-modified alumina with silica coating the particles' surfaces. This technique yields the 
zirconia with a reactive silica outer layer favorable to silanization and the following resin cementing procedures $[3,14]$.

Another alternative method for ceramic surface conditioning is laser irradiation [15]. Lasers were proposed to modify the surfaces of materials in a relatively safe and easy way [16-19], but only limited studies on all ceramic materials laser treatments are available [16-18, 20]. One of the most often used lasers in research, as well as in clinical practice, is the erbium-doped yttrium aluminum garnet (Er:YAG). This laser operates at the wavelength of $2,940 \mathrm{~nm}$, and one of its distinctive features is to operate in a pulse mode. Er:YAG with appropriate parameters can create an irregular surface that enhances the micromechanical retention to ceramic materials [20]. Still, high laser intensity can damage surface properties, resulting in crack formation and consequently low bond strength values [21].

First, there are several procedures capable of achieving a strong bond with Y-TZP. However, this bond strength should remain adequate over years in the surrounding oral environment as follows: temperature shocks, $\mathrm{pH}$ variation, humidity, and mastication forces. Bond strength can decay with time, causing retention loss and microleakage increases. One of the main mechanisms of the zirconia/resin interface degradation can be thermal fatigue that can result in stress affecting the bond interface, e.g., thermal expansion and contraction [22], and could lead to unequal changes in dimensions and eventually to bond failure [23].

Many factors like ceramic wettability, surface roughness, or bonding agents' composition can influence the quality and stability of the resin cement-zirconia adhesion [24]. If, on one hand, little data is available concerning the roughening capacity of the Er:YAG laser for enhanced microretention of the YTZP for optimized adhesive luting procedures [20], on the other hand, there is still controversy about the best luting system for Y-TZP ceramics [25]. It is important to study if laser irradiation is a valuable alternative method for high-strength ceramics' surface conditioning, capable of providing a resin-zirconia bond with high efficiency and, foremost, durability.

The aim of this study is to evaluate the thermocycling effect on the microshear bond strength $(\mu \mathrm{SBS})$ of different self-adhesive resin cements to zirconia when using a tribochemical silica coating and Er:YAG as surface conditioners. The null hypothesis was that neither the different surface conditioning methods, the thermocycling effect, nor the resin cement composition modifies the $\mu$ SBS to zirconia ceramics.

\section{Materials and methods}

\section{Specimen preparation}

The study used 240 square-like specimens (measuring $3 \times 3 \times 1 \mathrm{~mm}$ ) of densely sintered Y-TZP (Cercon ${ }^{\circledR}$, DeguDent, Hanau, Germany). The specimens' surfaces were wet-polished with 600-grit silicon carbide paper. Zirconia samples were randomly assigned to four experimental surface treatments $(n=60)$ (Table 1).

\section{No surface treatment was applied (NT).}

2. Tribochemical silica coating using Rocatec system (ROC) (Rocatec ${ }^{\mathrm{TM}}$ Soft, 3 M Espe, Seefeld, Germany). The surfaces were treated by means of tribochemical silica coating ( $30 \mu \mathrm{m}$ alumina coated with silica particles) that was applied perpendicularly for $20 \mathrm{~s}$, at a working distance of $10 \mathrm{~mm}$, and a pressure of 2.8 bar; silanization was performed before bonding with Rely $\mathrm{X}^{\mathrm{TM}}$ ceramic primer ( $3 \mathrm{M}$ Espe, Seefeld, Germany) following the manufacturer's instructions.

3. Er:YAG laser irradiation (LAS). The surfaces were coated with graphite prior to laser irradiation to increase energy of absorption, and the laser equipment used was an Er:YAG laser (Key laser $3^{+}$, $\mathrm{KaVo}$, Biberach/Riß, Germany) emitting a 2,940 nm wavelength. A no-contact probe was used perpendicular to the surface with a working distance of $5 \mathrm{~mm}$. The surfaces were irradiated until the whole ceramic area was scanned using a fine water spray. The pulse repetition was set at $10 \mathrm{~Hz}$ and energy intensity was set at $200 \mathrm{~mJ}[20]$.

4. Er:YAG laser followed by tribochemical silica coating (LAROC). Both procedures were developed as previously described. 
Table 1. Study design with the distribution of the samples among the different groups

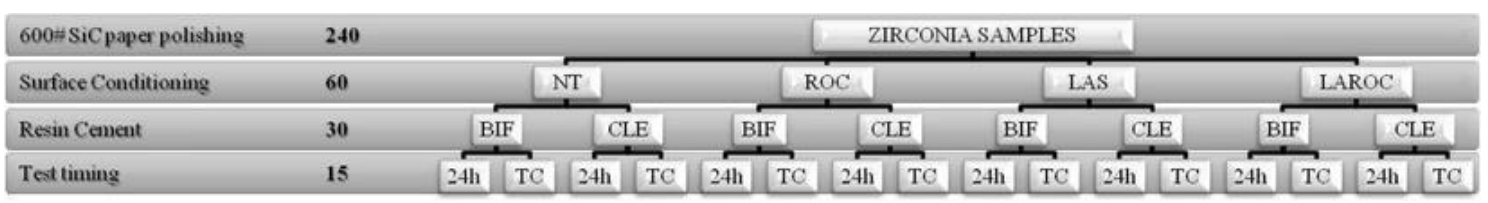

\section{Luting procedure}

Each group was divided into two subgroups depending on the luting system applied. Two selfadhesive resin cements were used as follows: (A) BiFix ${ }^{\circledR}$ SE (BIF) (BiFix® ${ }^{\circledR}$ SE, VOCO, Cuxhafen, Germany) and (B) Clearfil ${ }^{\mathrm{TM}}$ SA cement (CLE) (Clearfil ${ }^{\mathrm{TM}}$ SA Cement, Kuraray, Osaka, Japan) (Table 2). Adhesion procedures were performed at room temperature according to manufacturer's recommendations.

Table 2. Materials brands, composition, and technical procedures used in the study

\begin{tabular}{|c|c|c|c|c|}
\hline Material & Manufacturer & Batch nr & Composition & Technical procedures \\
\hline Cercon $®$ & $\begin{array}{l}\text { DeguDent } \\
\text { GmbH, } \\
\text { Germany }\end{array}$ & Lot:200233692 & $\begin{array}{l}\text { Zirconium oxide }(92 \%) \text {, yttrium oxide }(5 \%) \text {, } \\
\text { hafnium oxide }(<2 \%) \text {, aluminum oxide }+ \text { silicon } \\
\text { oxide }(<1 \%)\end{array}$ & $\begin{array}{l}\text { Sinter the ceramic cylinders in a } \\
\text { special oven (Cercon Heat, } \\
\text { Dentsply) keeping the temperature } \\
\text { at } 1,350^{\circ} \mathrm{C} \text { for } 6 \mathrm{~h} \text {. }\end{array}$ \\
\hline BiFix ${ }^{\circledR}$ SE & $\begin{array}{l}\text { VOCO, } \\
\text { Cuxhafen, } \\
\text { Germany }\end{array}$ & $\begin{array}{l}\text { Lot: } 1221264 \\
\text { Ref } 1794\end{array}$ & $\begin{array}{l}\text { Bis-GMA, UDMA, Gly-DMA, phosphate } \\
\text { monomers, initiators, stabilizers, glass fillers, } \\
\text { aerosol silica (filler }=70 \text { wt. } \% \text { ) }\end{array}$ & $\begin{array}{l}\text { Dispense the cement from a dual- } \\
\text { barreled automix syringe and a } \\
\text { spiral mixing tip. Apply the cement } \\
\text { on the ceramic surface. Self-cure } \\
\text { for } 5 \text { min and light-cure each axial } \\
\text { surface for } 40 \mathrm{~s} \text {. }\end{array}$ \\
\hline $\begin{array}{l}\text { Clearfili }^{\mathrm{TM}} \\
\text { SA Cement }\end{array}$ & $\begin{array}{l}\text { Kuraray, } \\
\text { Osaka, Japan }\end{array}$ & $\begin{array}{l}\text { Lot: 0056AA } \\
\text { Ref \#2800 EU }\end{array}$ & $\begin{array}{l}\text { 10-MDP, hydrophobic aromatic dimethacrylate, } \\
\text { hydrophobic aliphatic dimethacrylate, colloidal } \\
\text { silica, barium glass (filler } 66 \text { wt. } \% \text { ) }\end{array}$ & $\begin{array}{l}\text { Dispense the cement from a dual- } \\
\text { barreled automix syringe and a } \\
\text { spiral mixing tip. Apply the cement } \\
\text { on the ceramic surface. Self-cure } \\
\text { for } 5 \text { min and light-cure each axial } \\
\text { surface for } 40 \mathrm{~s} \text {. }\end{array}$ \\
\hline $\begin{array}{l}\text { Rocatec } \\
\text { Soft }\end{array}$ & $\begin{array}{l}3 \text { M Espe, } \\
\text { Seefeld, } \\
\text { Germany }\end{array}$ & Lot: 410254 & $30 \mu \mathrm{m}$ silica-modified alumina oxide & $\begin{array}{l}\text { Sandblasting for } 20 \mathrm{~s} \text { at } 28 \mathrm{Bar} \text { and } \\
10 \mathrm{~mm} \text { of distance. }\end{array}$ \\
\hline $\begin{array}{l}\text { Rely XTM } \\
\text { Ceramic } \\
\text { primer }\end{array}$ & $\begin{array}{l}3 \text { M Espe, } \\
\text { Seefeld, } \\
\text { Germany }\end{array}$ & $\begin{array}{l}\text { Lot: N375992 } \\
\text { Ref } 2721\end{array}$ & $\begin{array}{l}\text { Ethyl alcohol, water, } \\
\text { Methacryloxypropyltrimethoxysilane }\end{array}$ & $\begin{array}{l}\text { Using a brush apply on the zirconia } \\
\text { bonding surface for } 40 \mathrm{~s} \text {. Gently air } \\
\text { dry. }\end{array}$ \\
\hline
\end{tabular}

After preparing the zirconia specimens, plastic molds (Tygon, Norton Performance Plastic Co, Cleveland, USA) with an inner diameter of $1 \mathrm{~mm}$ and height of $2 \mathrm{~mm}$ were positioned in the center of the specimens. The cement was carefully packed into the tube against the substrate, and stubs were lightpolymerized for $40 \mathrm{~s}$ (XL 3000, $3 \mathrm{M} / \mathrm{ESPE}$; light intensity $500 \mathrm{~mW} \mathrm{~cm}{ }^{-2}$, distance 0 ) from the top of the stub and from two lateral directions at the contact area. The mold was gently removed and the cement cylinder was light cured for extra $40 \mathrm{~s}$. Thereby, a small cylinder of resin cement with $1 \mathrm{~mm}$ in diameter and $2 \mathrm{~mm}$ in height was bonded to the ceramic surface. Thirty specimens were created in each subgroup. Specimens were stored for $24 \mathrm{~h}$ in distilled water at $37^{\circ} \mathrm{C}$. After $24 \mathrm{~h}$, half of the specimens from each subgroup $(n=15)$ were tested immediately for microshear bond strength. The other half was subjected to thermocycling (TC) in distilled water for 5,000 cycles between 5 and $55^{\circ} \mathrm{C}$. The dwelling time at each temperature was $30 \mathrm{~s}$, and the transfer time was $2 \mathrm{~s}$. 


\section{Microshear bond strength test}

Each ceramic plate with its cement cylinder was fixed with cyanoacrylate adhesive (Zapit, Dental Ventures of America, Corona, USA) to a microshear device adapted to a universal testing machine (AGSX Autograph, Shimadzu Corporation, Kyoto, Japan). A shear load, cross-head speed of $0.5 \mathrm{~mm} / \mathrm{min}$, was applied until fracture. Bond strength values were calculated by dividing the maximum load recorded on failure by the circular bonding area in square millimeters and expressed in $\mathrm{MPa}$.

After fracturing, the ceramic surfaces were evaluated with a stereoscopic zoom microscope (SMZ800, Nikon Corporation, Tokyo, Japan) at $\times 40$ magnifications to assess the failure mode and classify it as adhesive (at the cement/ceramic interface, including pretesting failure) or mixed (with both adhesive and cohesive phases).

\section{Statistical analysis}

Descriptive statistics used the mean of shear bond strength (SBS) (in megapascal) and its standard deviation (SD). A two-way analysis of variance and Bonferroni's post hoc correction were used to determine the statistical significance of any intergroup differences in mean SBSs. Student's $t$ tests were performed for comparing the SBS between cement groups. Chi-square tests and odds ratio were used in two-by-two tables for quantifying the risk of adhesive failure versus mixed failure among subgroups. A linear regression analysis was implemented using a stepwise selection method for introducing all potential predictors of SBSs (i.e., surface, cement, and aging). Significance for all statistical tests was predetermined at $p<0.05$. All the statistical analyses were performed using SPSS 18.0 for Windows (SPSS, Chicago, IL).

\section{SEM examination}

Representative samples from each subgroup were prepared for scanning electron microscopy (SEM) analysis. Samples were dehydrated for $48 \mathrm{~h}$ in a desiccator (Sample Dry Keeper Simulate Corp., Tokyo, Japan) and sputter coated with a $10 \mathrm{~nm}$ platinum layer in a Polaron E5100 SEM coating unit (Polaron Equipment Ltd., Hertfordshire, England, UK). The morphology of the debonded zirconia surfaces was then examined with a variable-pressure SEM (Zeiss EVO MA 25; Carl Zeiss, Jena, Germany).

Specific surface areas were explored, focusing with different magnifications (from $\times 70$ to $\times 1,000$ ) to identify possible differences in the surface topography and morphology of the debonded interfaces among the experimental groups.

\section{Results}

\section{Microshear bond strength test}

Mean and SD of the $\mu$ SBS are summarized in Table 3. According to these results, the cement type, the surface treatment, and the artificial aging significantly influenced the shear bond strength to the zirconia (Table 3).

Table 3. Microshear bond strength mean $(\mathrm{MPa} \pm$ standard deviation $)$ and ANOVA results

\begin{tabular}{|c|c|c|c|c|}
\hline & \multicolumn{2}{|c|}{ BiFix SE (BIF) } & \multicolumn{2}{|c|}{ Clearfil SA (CLE) } \\
\hline & $24 \mathrm{~h}$ & Thermocycled (TC) & $24 \mathrm{~h}$ & Thermocycled (TC) \\
\hline No treatment (NT) & $7.5 \pm 5.6^{\mathrm{B}, \mathrm{a}}$ & $0.0 \pm 0.0^{\mathrm{A}, \mathrm{b}}$ & $6.8 \pm 3.4^{\mathrm{C}, \mathrm{a}}$ & $1.5 \pm 2.6^{\mathrm{C}, \mathrm{b}}$ \\
\hline Rocatec (ROC) & $17.3 \pm 6.6^{\mathrm{A}, \mathrm{a}}$ & $1.9 \pm 1.5^{\mathrm{A}, \mathrm{b}}$ & $15.8 \pm 4.8^{\mathrm{A}, \mathrm{a}}$ & $15.3 \pm 5.8^{\mathrm{A}, \mathrm{a}}$ \\
\hline Er:YAG (LAS) & $5.7 \pm 2.3^{\mathrm{B}, \mathrm{a}}$ & $1.8 \pm 3.8^{\mathrm{A}, \mathrm{b}}$ & $6.9 \pm 2.0^{\mathrm{C}, \mathrm{a}}$ & $0.0 \pm 0.0^{\mathrm{C}, \mathrm{b}}$ \\
\hline Er:YAG plus Rocatec (LAROC) & $18.9 \pm 4.6^{\mathrm{A}, \mathrm{a}}$ & $0.9 \pm 2.2^{\mathrm{A}, \mathrm{c}}$ & $11.1 \pm 3.8^{\mathrm{B}, \mathrm{b}}$ & $9.9 \pm 3.5^{\mathrm{B}, \mathrm{b}}$ \\
\hline
\end{tabular}


When using BIF, without thermocycling, ROC and LAROC showed similar $\mu$ SBS and were significantly higher than NT and LAS (which were not significantly different). After TC, all BIF groups had identical bond strength results, showing that adhesion effectiveness had decreased to values near to zero (Table 3), when compared with the previous cited groups. In the specimens cemented with CLE, ROC exhibited the bond strengths that were statistically the highest, regardless of the thermocycling process. The LAROC group achieved higher $\mu$ SBS values than NT and LAS, and had similar results preor post-artificial aging.

Without thermocycling, BIF registered similar values to CLE, except with LAROC treatment. When the surface was conditioned with LAROC, the highest $\mu$ SBS results were observed in the BIF samples. After TC, CLE had higher $\mu$ SBS values than BIF when ROC or LAROC was used, and the other groups presented identical values to BIF. A single T-test comparison of the $\mu$ SBS between BIF $(n=120 ;$ mean $6.6 \pm 8.0 \mathrm{Mpa})$ versus CLE $(n=120$; mean $8.4 \pm 6.5 \mathrm{Mpa})$ confirmed the CLE's global higher performance, with an almost significant $p$ value of 0.06 (result not shown).

The failure mode distributions in the experimental groups are outlined in Table 4. Within the BIF group, the samples mainly failed adhesively. Only the samples where Rocatec was used, with or without the laser, and that were tested after $24 \mathrm{~h}$ presented mixed failures. After TC, $100 \%$ of the BIF samples failed adhesively. Using CLE, in general, NT and LAS groups failed adhesively without considering the artificial aging process. In combination with ROC, with or without the laser, when the samples were tested $24 \mathrm{~h}$ later, mostly mixed failures were observed. Thermocycling influenced only the LAROC group failure mode that registered a majority of mixed pattern in $24 \mathrm{~h}$ that became adhesive after the aging process; ROC maintained a higher percentage of mixed failures (Table 4).

Table 4. Failure mode distribution (in percentage) in the experimental groups

\begin{tabular}{|c|c|c|c|c|c|c|c|c|}
\hline & \multicolumn{4}{|c|}{ BIF } & \multicolumn{4}{|c|}{ CLE } \\
\hline & \multicolumn{2}{|c|}{$24 \mathrm{~h}$} & \multicolumn{2}{|c|}{$\mathrm{TC}$} & \multicolumn{2}{|c|}{$24 \mathrm{~h}$} & \multicolumn{2}{|c|}{$\mathrm{TC}$} \\
\hline & A & M & A & M & A & M & A & M \\
\hline NT & 86.6 & 13.3 & 100 & - & 93.3 & 6.6 & 100 & - \\
\hline ROC & 46.6 & 53.3 & 100 & - & 20 & 80 & 6.6 & 93.3 \\
\hline LAS & 100 & - & 100 & - & 73.3 & 26.6 & 100 & - \\
\hline LAROC & 33.3 & 66.6 & 100 & - & 40 & 60 & 66.6 & 33.3 \\
\hline
\end{tabular}

$A$ adhesive failure, $M$ mixed failure

Given the similarities between NT and LAS and between ROC and LAROC results, the surface treatment groups were assembled into the following two groups: (1) no surface treatment or laser and (2) Rocatec with or without laser. A two-by-two analysis of the type of failures distribution (adhesive vs. mixed) was made according to the surface treatment between both BIF and CLE subgroups, which is evident in Table 5 .

Table 5. Type of failures (adhesive vs. mixed) percentages distribution according to the surface treatment among both BIF and CLE subgroups

\begin{tabular}{|c|c|c|c|c|}
\hline & \multicolumn{2}{|c|}{ BIF } & \multicolumn{2}{|c|}{ CLE } \\
\hline & NT + LAS & $\mathrm{ROC}+\mathrm{LAROC}$ & $\mathrm{NT}+\mathrm{LAS}$ & $\mathrm{ROC}+\mathrm{LAROC}$ \\
\hline Adhesive failure (\%) & 97 & 70 & 92 & 32 \\
\hline \multirow[t]{2}{*}{ Mixed failure (\%) } & 3 & 30 & 8 & 68 \\
\hline & $\begin{array}{r}\mathrm{Cl} \\
\mathrm{OR}(\mathrm{a}\end{array}$ & $\begin{array}{l}p<0.001 \\
\text { nixed) }=12.4 \\
.7-56.5\end{array}$ & $\begin{array}{r}\mathrm{Cl} \\
\mathrm{OR}(\mathrm{a}\end{array}$ & $\begin{array}{l}p<0.001 \\
\text { nixed) }=23.7 \\
.2-68.9\end{array}$ \\
\hline
\end{tabular}

$O D$ odds ratio, $C I$ confidence interval 
Within the BIF subgroup, the risk of getting an adhesive failure is 12.4 times more when NT or LAS were applied (OR adhesive/mixed =12.4), and the percentage values of adhesive failures for BIF subgroup were significantly higher (chi 15.36, $p<0.001$ ) (Table 5). Otherwise, using CLE in combination with ROC or LAROC, the percentage of mixed failures was significantly higher (chi $45.69 ; p<0.001$ ) and the risk of an adhesive failure was 23.7 (OR adhesive/mixed =23.7) when NT or LAS was used.

A significant linear regression model $(\mathrm{F}=104.558 ; p<0.001)$ confirmed that SBS could be predicted (corrected $\mathrm{R}^{2}=0.57$ ) when surface treatment, artificial aging, and cement are known. The strongest predictor is the surface treatment (codified as ROC or LAROC vs. NT or LAS) that increases the baseline $\mu \mathrm{SBS}$ (expected to range from 5.2 to $7.6 \mathrm{MPa})$ in 6.7 to $9.2 \mathrm{MPa}(\mathrm{T}=12.58 ; p<0.001)$. The following predictor is the artificial aging $(\mathrm{T}=-11.95 ; p<0.001)$, which reduces the baseline $\mu$ SBS in 6.2-8.7 MPa. The weakest, although significant predictor of the $\mu \mathrm{SBS}$, is the type of cement, which implies that $\mu$ SBS could be increased from 0.6 to 3.0 MPa if we use CLE instead of BIF ( $\mathrm{T}=2.85 ; p=0.005)$.

\section{SEM analysis}

\section{Failure mode analysis}

Representative SEM images of debonded zirconia surfaces after $\mu$ SBS are presented in Fig. 1. A zirconia sample with different magnifications is shown in each picture. First, in the upper right, a lower magnification (approximately $\times 70$ ) used to assess the type of failure. Details of the debonded area obtained are highlighted with a magnified view (about $\times 700$ ). Images $\mathrm{A}, \mathrm{B}$, and E present adhesive failure patterns with no luting residuals remaining. Images $\mathrm{C}, \mathrm{D}, \mathrm{F}, \mathrm{G}$, and $\mathrm{H}$ demonstrate mixed failures with cement remnants layering on the zirconia surface, namely in $\mathrm{C}, \mathrm{D}, \mathrm{G}$, and $\mathrm{H}$, that correspond to ROC and LAROC groups, where a large cohesive phase is visible.

\section{Surface treatment analysis}

The SEM micrographs in Fig. 2 show the zirconia surface morphology after the different surface conditioning methods were applied. Image A represents the NT group with marked scratches in different directions as a result of the polishing procedure with silicon carbide paper. In the ROC group, image B, due to the high-speed particles' impact, the porcelain substrate suffered surface modification and edgeshaped microretentions are present. Signs of fusion and solidification may be observed in Image C (LAS group), but no superficial cracks are observed, and the scratches, resulting from the polishing, are still visible after the laser treatment. Finally, in image D, an irregular and rough appearance, similar to image $\mathrm{B}$, is evident. Although the laser alters the zirconia surface, the Rocatec ${ }^{\circledR}$ overcomes that, and LAROC (image D) produces an identical surface conditioning to ROC group (image B). 


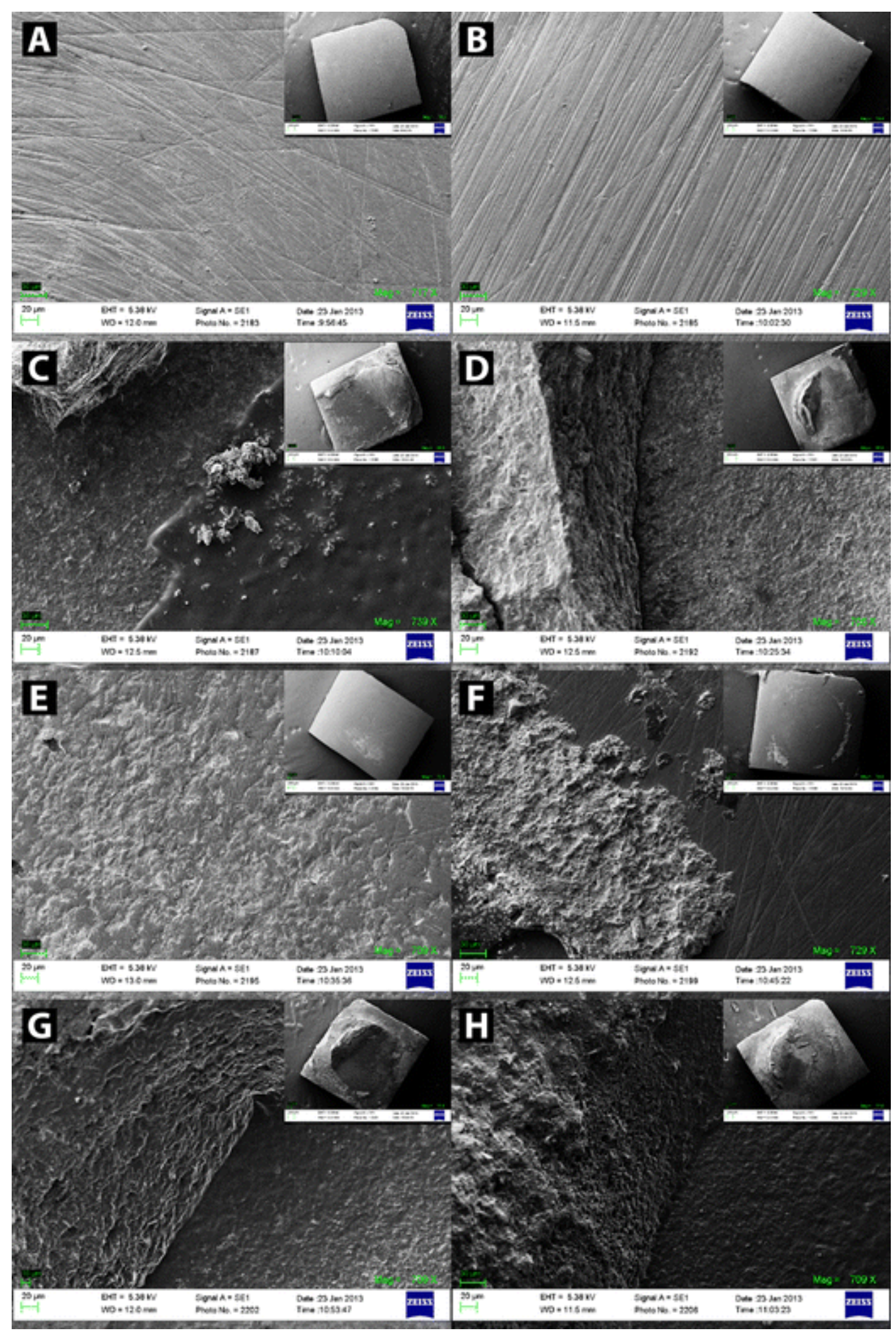

Fig. 1. SEM ( $\times 70$ and $\times 700$ magnification) images of zirconia surfaces to assess the failure type of each subgroup, a BIF NT, b CLE NT, $\mathbf{c}$ BIF ROC, $\mathbf{d}$ CLE ROC, e BIF LAS, $\mathbf{f}$ CLE LAS, $\mathbf{g}$ BIF LAROC, and $\mathbf{h}$ CLE LAROC. Images A, B, and E show adhesive failure and a complete detachment of the luting agent from the porcelain substrate. Pictures C, D, F, G, and $\mathrm{H}$ illustrate mixed failures with presence of cement residues on the zirconia surface 


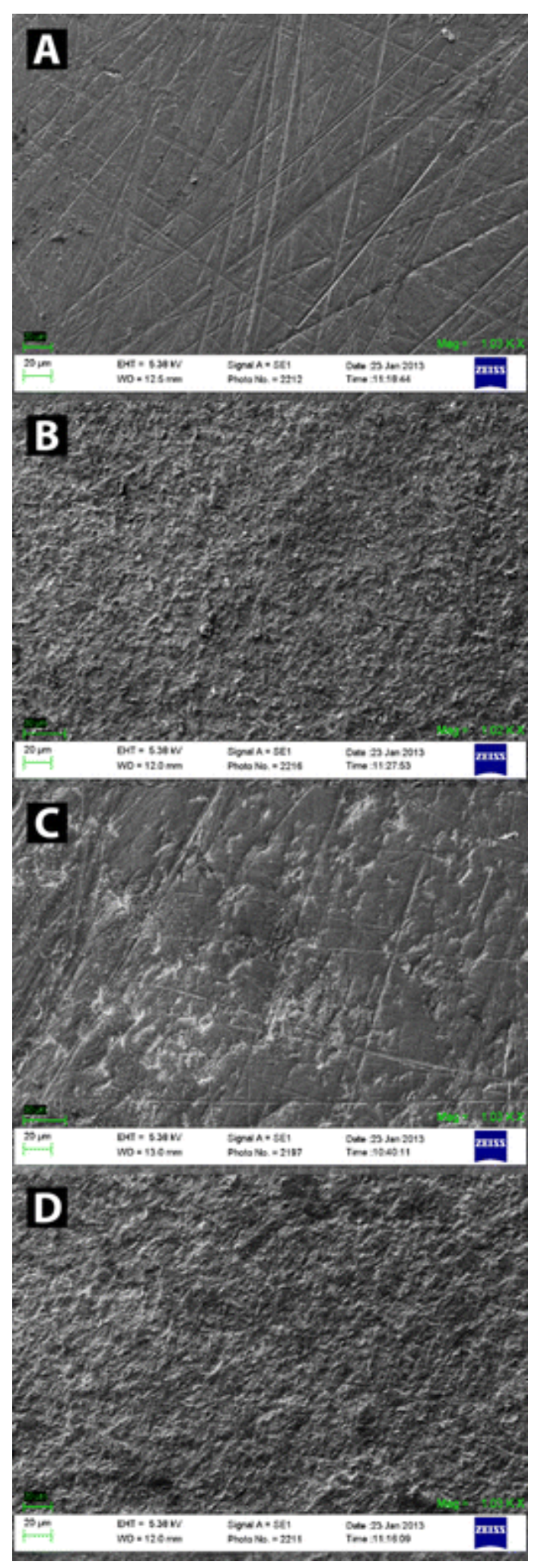

Fig. 2. SEM ( $\times 1000$ magnifications) images of zirconia after the different surface treatments used. a NT (no treatment), b ROC (Rocatec ${ }^{\mathrm{TM}}$ Soft), c LAS (Er:YAG laser with $200 \mathrm{~mJ}$ ), and $\mathbf{d}$ LAROC (laser followed by silica coating) 


\section{Discussion}

This study assessed the effects of surface conditioning and resin cements in the adhesion shear bond strength to zirconia under aging. Our findings make us reject the null hypothesis proposed because significant differences among the experimental groups were found as detailed next.

A $\mu$ SBS significant predictor was the type of cement, which implies that its value could be increased from 0.6 to 3.0 MPa if CLE was used instead of BIF. Both cements are self-adhesive resin cements and were used in a single step on the zirconia surface (following the manufacturers' instructions). However, given their common composition, present in most resin-based materials (Table 2), we should highlight the 10-MDP existence in CLE luting system. This acidic functional monomer was reported as able of chemically adhere to zirconium oxide by interacting with the $-\mathrm{OH}$ radical in the ceramic surface $[11,14$, 26] and rated as relatively hydrolysis stable due to its long carbonyl chain [27].

The surface conditioning procedure, the strongest predictor factor in the regression model used, seems to be a more relevant factor in bonding to zirconia surface, contrary to other studies that advocate the cement choice as fundamental to attain reliable adhesion to zirconia [15, 28]. Both cements had higher $\mu$ SBS values after silica coating with the ROC and LAROC groups. SEM observations revealed considerable qualitative differences in the ceramic surface architecture after the different conditioning methods (Fig. 2). These findings can be directly related to bond strength results, once the treated surface is rough with a uniform presence of shaped microretentions and shallow pits, but no microcracks (Fig. 2b, d). The resultant improvement in resin bond strength can be explained not only by the attained roughness, but also because the silica coating process allows chemical coupling through the silane [9, 12]. Prior to cement application, the ceramic surface irregularities, resulting from Rocatec ${ }^{\mathrm{TM}}$ particles' impact, were infiltrated by Rely $\mathrm{X}^{\mathrm{TM}}$ ceramic primer, a pre-hydrolyzed 3-methacryloxypropyltrimethoxysilane (3MPS) ready for direct use as supplied by the manufacturer. Silane coupling agents have silicon linked to reactive organic radicals, which become chemically bonded to resin molecules and form siloxane linkages with the silica-coated surface. Their use enhances the ceramic wettability (producing better contact and infiltration of the resin in the ceramic irregularities), protects against moisture, and creates an acid environment that may support the bonding reaction [29].

Both cements recorded similar $\mu$ SBS when irradiated with Er:YAG and without surface treatment, regardless of thermocycling process. Although laser treatment creates a rougher surface (Fig. 2c), it does not improve bond strength. The surface irregularities created by Er:YAG (probably due to local increases of the substrate temperature that generates an erosive effect) have insufficient microdepth without micromechanical retention. This results in limited penetration of the cement. Er:YAG laser had minimal impact on zirconia, since it is a water-free material that present a white and opaque coloration. The Rocatec $^{\mathrm{TM}}$ employment after the laser in the LAROC treatment easily overcame and covered the LAS surface modification, and a similar surface to ROC group was observed (Fig. 2b, d). These results are in line with a recent study findings [28].

Bond strength results demonstrate that laser irradiation was less effective in improving bond strength than tribochemical silica coating, for both resin cements. A recent study also registered low bond strength of all luting systems tested to Er:YAG irradiated zirconia. The authors suggested that during laser irradiation, the micro-explosions could form debris which might adhere to the melted ceramic surfaces. Such a layer would be able to bond strongly to the resin cement but would be poorly attached to the infralayer surface, resulting in low bond strengths [28]. However, this hypothesis was not confirmed, and further research is needed. While Subaşi et al. [28, 30] and Akyil et al. [31] reported similar results to our study, others suggested that Er:YAG laser significantly increased the SBS of ceramic to dentin [20, 32, 33].

Thermocycling affected negatively all the specimens' bond strength, except when CLE was used in ROC and LAROC groups. A slight decrease in bond strength was observed after TC, which was not statistically significant. The aging effect induced by thermocycling can occur by repetitive contraction/expansion stresses generated by different thermal coefficient of the restorative materials or by hydrolysis of the interfacial components (water can infiltrate and decrease the mechanical properties of the polymer matrix by swelling and reducing the frictional forces between the polymer chains) [23]. When silica coating was performed, CLE was able to adhere to the silica present on the ceramic surface through the interaction between 10-MDP monomer and 3-MPS, producing more durable bonding values, as demonstrated in previous studies [34, 35].

Failure modes were assessed and supported the bond strength results. Both cements in NT and LAS groups had a tendency to fail adhesively at the resin-zirconia interface, presenting the substrate surface free of cement residues (Fig. 1a, b, e), which is in accordance with the literature for other self-adhesive cements [3, 27]. Mixed failures were observed mostly in ROC and LAROC groups (Table 4). These are clinically preferred to adhesive failures because they are usually associated with high bond strength 
values [22], which is consistent with the data in Table 2. The high prevalence of mixed and adhesive failures indicates that the different results among experimental groups were caused by the differences of adhesive interface between the cements and the ceramic that was treated with distinct procedures [32].

In the present study, a lower power setting $(200 \mathrm{~mJ})$ was selected. Microcracks were not observed in SEM micrographs (Fig.2c), and the absence of cohesive ceramic fractures (Table 4) suggests that the laser treatment did not induced internal weakening in the ceramic. The principle effect of laser energy is the conversion of light energy into heat, and the most important interaction between laser and substrate is the absorption of energy by the substrate [16]. The mechanical properties of Y-TZP ceramics can be negatively affected by changes in temperature, which can induce phase transformation [20]. Higher laser power settings (400 and $600 \mathrm{~mJ}$ ) can cause excessive material deterioration, making them unsuitable as surface treatments for zirconia [16].

\section{Conclusion}

Results suggest that thermocycling does not affect $\mu$ SBS obtained in the resin-zirconia interface when applying a self-adhesive resin cement with 10-MDP in its composition over a zirconia surface pretreated with silica coating with or without Er:YAG. Nevertheless, the adhesive effectiveness is higher if the surface is only conditioned with silica coating (not applying the laser) despite the artificial aging process. The Er:YAG laser has been reported as creating thermomechanical effects on substrate; however, this study demonstrated that zirconia Er:YAG etching is not effective in increasing its bond strength to resin.

\section{Acknowledgments}

The authors would like to thank Dentsply (Germany), VOCO (Germany), Kuraray (Japan), and 3 M (Germany) for providing some of the materials used in this study. We also thank the Dental Lab Aragoneses (Madrid, Spain), Judith Gomez for their technical support, and Spanish Pulsed Laser Center (CLPU) for instrument (SEM) use in this research.

\section{References}

1. Denry I, Kelly JR (2008) State of the art of zirconia for dental applications. Dent Mater 24(3):299-307

2. Manicone PF, Iommetti PR, Raffaelli L (2007) An overview of zirconia ceramics: basic properties and clinical applications. J Dent 35(11):819-826

3. Blatz MB, Sadan A, Kern M (2003) Resin-ceramic bonding: a review of the literature. J Prosthet Dent 89(3):268274

4. Blatz M, Phark J-H, Ozer F, Mante F, Saleh N, Bergler M, Sadan A (2010) In vitro comparative bond strength of contemporary self-adhesive resin cements to zirconium oxide ceramic with and without air-particle abrasion. Clin Oral Investig 14(2):187-192

5. Ferracane JL, Stansburry JW, Burke FJT (2011) Self-adhesive resin cements - chemistry, properties, and clinical considerations. J of Oral Rehabil 38(4):295-314

6. Aboushelib M, Kleverlaan C, Feilzer A (2007) Selective infiltration-etching technique for a strong and durable bond of resin cements to zirconia-based materials. J Prosthet Dent 98(5):379-388

7. Phark JH, Duarte SJ, Blatz M, Sadan A (2009) An in vitro evaluation of the long-term resin bond to a new densely sintered high-purity zirconium-oxide ceramic surface. J Prosthet Dent 101(1):29-38

8. Aboushelib MN, Mirmohamadi H, Matinlinna JP, Kukk E, Ounsi HF, Salameh Z (2009) Innovations in bonding to zirconia-based materials. Part II: focusing on chemical interactions. Dent Mater 25(8):989-993

9. Atsu SS, Kilicarslan MA, Kucukesmen HC, Aka PS (2006) Effect of zirconium-oxide ceramic surface treatments on the bond strength to adhesive resin. J Prosthet Dent 95(6):430-436

10. Blatz MB, Sadan A, Martin J, Lang B (2004) In vitro evaluation of shear bond strengths of resin to denselysintered high-purity zirconium-oxide ceramic after long-term storage and thermal cycling. J Prosthet Dent 91(4):356-362

11. Wolfart M, Lehmann F, Wolfart S, Kern M (2007) Durability of the resin bond strength to zirconia ceramic after using different surface conditioning methods. Dent Mater 23(1):45-50

12. Paranhos MP, Burnett LHJ, Magne P (2011) Effect of Nd:YAG laser and CO2 laser treatment on the resin bond strength to zirconia ceramic. Quintessence Int 42(1):79-89

13. Ural Ç, Külünk T, Külünk Ş, Kurt M (2010) The effect of laser treatment on bonding between ceramic surface and resin cement. Acta Odontol Scand 68(6):354-359

14. Kern M, Wegner SM (1998) Bonding to zirconia ceramic: adhesion methods and their durability. Dent Mater 14(1):64-71

15. Oyagüe RC, Osorio R, da Silveira BL, Toledano M (2011) Comparison of bond stability between dual-cure resin cements and pretreated glass-infiltrated alumina ceramics. Photomed Laser Surg 29(7):465-475 
16. Cavalcanti AN, Pilecki P, Foxton RM, Watson TF, Oliveira MT, Giannini M, Marchi GM (2009) Evaluation of the surface roughness and morphologic features of Y-TZP ceramics after different surface treatments. Photomed Laser Surg 27(3):473-479

17. Ersu B, Yuzugullu B, Ruya YA, Canay S (2009) Surface roughness and bond strength of glass-infiltrated alumina-ceramics prepared using various surface treatments. J Dent 37(11):848-856

18. Gökçe B, Özpınar B, Dündar M, Çömlekoglu E, Sen BH, Güngör MA (2007) Bond strengths of all ceramics: acid versus laser etching. Oper Dent 32(2):168-173

19. Spohr AM, Borges GA, Júnior LH, Mota EG, Oshima HM (2008) Surface modification of In-Ceram zirconia ceramic by Nd:YAG laser, Rocatec system, or aluminum oxide sandblasting and its bond strength to a resin cement. Photomed Laser Surg 26(3):203-208

20. Cavalcanti AN, Foxton RM, Watson TF, Oliveira MT, Giannini M, Marchi GM (2009) Bond strength of resin cements to a zirconia ceramic with different surface treatments. Oper Dent 34(3):280-287

21. Akin H, Ozkurt Z, Kimalı O, Kazazoglu E, Ozdemir AK (2011) Shear bond strength of resin cement to zirconia ceramic after aluminum oxide sandblasting and various laser treatments. Photomed Laser Surg 29(12):797-802

22. Toledano M, Osorio R, Osorio E, Aguilera FS, Yamauti M, Pashley DH, Tay F (2007) Durability of resin-dentin bonds: effect of direct/indirect exposure and storage media. Dent Mater 23(7):885-892

23. De Munck J, Van Landuyt K, Peumans M, Poitevin A, Lambrechts P, Braem M, Van Meerbeek B (2005) A critical review of the durability od adhesion to tooth tissue: methods and results. J Dent Res 84(2):118-132

24. Yang B, Lange-Jansen HC, Scharnberg M, Wolfart S, Ludwig K, Adelung R, Kern M (2008) Influence of saliva contamination on zirconia ceramic bonding. Dent Mater 24(4):508-513

25. Gomes AL, Oyagüe RC, Lynch CD, Montero J, Albaladejo A (2012) Influence of sandblasting granulometry and resin cement composition on microtensile bond strength to zirconia ceramic for dental prosthetic frameworks. $\mathrm{J}$ Dent. doi:10.1016/j.jdent.2012.09.013

26. Yoshida K, Tsuo Y, Astuta M (2006) Bonding of dual-cured resin cement to zirconia ceramic using phosphate acid ester monomer and zirconate coupler. J Biomed Mater Res B Appl Biomater 77(1):28-33

27. de Oyagüe RC, Monticelli F, Toledano M, Osorio E, Ferrari M, Osorio R (2009) Influence of surface treatments and resin cement selection on bonding to densely sintered zirconium oxide ceramic. Dent Mater 25(2):172-179

28. Subaşi MG, Inan O (2011) Evaluation of the topographical surface changes and the roughness of zirconia after different surface treatments. Lasers Med Sci 27(4):735-742

29. Matinlinna JP, Vallitu PK (2007) Bonding of resin composites to etchable ceramic surfaces: an insight overview of the chemical aspects on surface conditioning. J Oral Rehabil 34(8):622-630

30. Subaşi MG, Inan O (2012) Influence of surface treatments and resin cement selection on bonding to zirconia. Lasers Med Sci [Epub ahead of print]

31. Akyil MS, Uzun IH, Bayindir F (2010) Bond strength of resin cement to yttrium-stabilized tetragonal zirconia ceramic treated with air abrasion, silica coating, and laser irradiation. Photomed Laser Surg 28(6):801-808

32. Usumez A, Hamdemirci N, Kotoglu BY, Parlar O, Sari T (2013) Bond strength of resin cement to zirconia ceramic with different surface treatments. Lasers Med Sci 28(1):259-266

33. Akin H, Tugut F, Akin GE, Mutaf B (2012) Effect of Er:YAG laser application on the shear bond strength and microleakage between resin cements and Y-TZP ceramics. Lasers Med Sci 27(2):333-338

34. Akgungor G, Sen D, Aydin M (2008) Influence of different surface treatments on the short-term bond strength and durability between a zirconia post and a composite resin core material. J Prosthet Dent 99(5):388-399

35. May LG, Passos SP, Capelli DB, Ozcan M, Bottino MA, Valandro LF (2010) Effect of silica coating combined to a MDP based primer on the resin bond to Y-TZP ceramic. J Biomed Mater Res B Appl Biomater 95(1):69-74 